\title{
14.3
}

\section{Идентификация Н-связей кальцинированного аортального клапана}

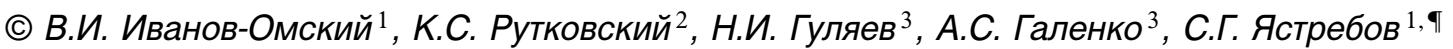 \\ ${ }^{1}$ Физико-технический институт им. А.Ф. Иофффе РАН, Санкт-Петербург, Россия \\ ${ }^{2}$ Санкт-Петербургский государственный университет, Санкт-Петербург, Россия \\ ${ }^{3}$ Военно-медицинская академия им. С.М. Кирова, Санкт-Петербург, Россия \\ ฯ E-mail: yastrebov@mail.ioffe.ru
}

Поступило в Редакцию 19 марта 2019г.

В окончательной редакции 10 июня 2019г.

Принято к публикации 10 июня 2019 г.

\begin{abstract}
Методом инфракрасной спектроскопии нарушенного полного внутреннего отражения измерены и проанализированы спектры поглощения субэндотелиальной области створок аортального клапана пациента, страдающего кальцинированным стенозом аорты, и здорового человека. Для сравнения исследованы спектры здоровой кости и аортального клапана свиньи. Исследования выполнены в диапазоне частот $2500-3600 \mathrm{~cm}^{-1}$. С помощью разложения на гауссовы компоненты исследована структура полосы поглощения в этой спектральной области. Проведена оценка энергий водородных связей с участием групп О-Н. Показано, что из всех исследованных образцов энергия Н-связи между гидроксильными группами достигает своего максимального значения в образце костной ткани.
\end{abstract}

Ключевые слова: водородная связь, кальцинозы, гидроксиапатит.

DOI: 10.21883/PJTF.2019.18.48233.17792

С увеличением продолжительности жизни населения промышленно развитых стран значительно возрастает актуальность исследований, посвященных изучению основ патогенеза заболеваний, присущих лицам пожилого и старческого возраста. Одним из наиболее ярких примеров такого рода патологии может служить кальцинированный аортальный стеноз - заболевание, развивающееся главным образом у лиц старше 70 лет, основное проявление которого заключается в кальцинации створок аортального клапана и связанных с этим расстройствах гемодинамики.

Патогенез кальцинированного аортального стеноза до конца неясен, соответственно в настоящее время не разработано и сколь-нибудь эффективных методов его профилактики, что автоматически делает актуальными исследования, посвященные выявлению основ этого загадочного процесса, которые могут в итоге привести к разработке средств его профилактики и лечения. В патогенезе этой группы заболеваний могут играть роль особенности формирования водородных связей как при образовании самих кальцинатов, так и между кальцинатами и остатками аминокислот в белках $[1,2]$. В работе [2] высказана гипотеза нуклеации нанокластеров костной ткани - гидроксиапатита - при участии водородной связи. В [1] с помощью методов рентгеновской дифракции показано, что нуклеация гидроксиапатита происходит в поровом пространстве субэндотелиальных структур аорты, доступ к которым току крови открывается вследствие развития патологического состояния - эндотелиальной дисфункции. В настоящей работе с помощью метода ИК-спектроскопии нарушенного полного внутреннего отражения (НПВО) подтверждается эта гипотеза. Особенностью данного метода является возможность измерения ИК-спектров с приповерхностной области образцов, т.е. в случае аортальных полулуний получения информации о колебаниях атомов в ближнем порядке, находящихся в субэндотелиальной области.

Известно, что водородная связь (Н-связь), будучи наиболее слабой среди межмолекулярных взаимодействий, обладает способностью обратимого разрушения и восстановления под действием теплового движения молекул при характерных для живого организма температурах. В настоящей работе приведены результаты сравнительного анализа структуры полосы ИК-поглощения белковых тканей различного происхождения, причем основное внимание обращено на комбинированную полосу, называемую Амид А. Интерес к ней определяется прежде всего тем, что она содержит линии поглощения гидроксильными $(-\mathrm{OH})$ и аминовыми $\left(=\mathrm{NH}\right.$ и $\left.-\mathrm{NH}_{2}\right)$ группами, участвующими в образовании комплексов с Н-связями.

Если влияние образования Н-связей на колебательные частоты ОН-групп и их интенсивности довольно хорошо изучено [3,4], то про азотсодержащие группы этого сказать нельзя. По этой причине в дальнейшем для характеристики Н-связей более детально рассматриваются только первые, проведена оценка величины их энергий [4]. Для анализа выбраны образцы разнородных тканей: (i1) аортальный клапан здорового мужчины; (i2) фрагмент створки аортального клапана пациента с кальцинированным стенозом аорты; (i3) фрагмент здоровой кости; (i4) синтетический коллаген и для сравнения клапан свиньи. Образцы тканей у пациента с кальцинированным аортальным стенозом брали при оперативном вмешательстве (протезировании клапана). Кальцинированные полулуния высушивались. Взвешен- 


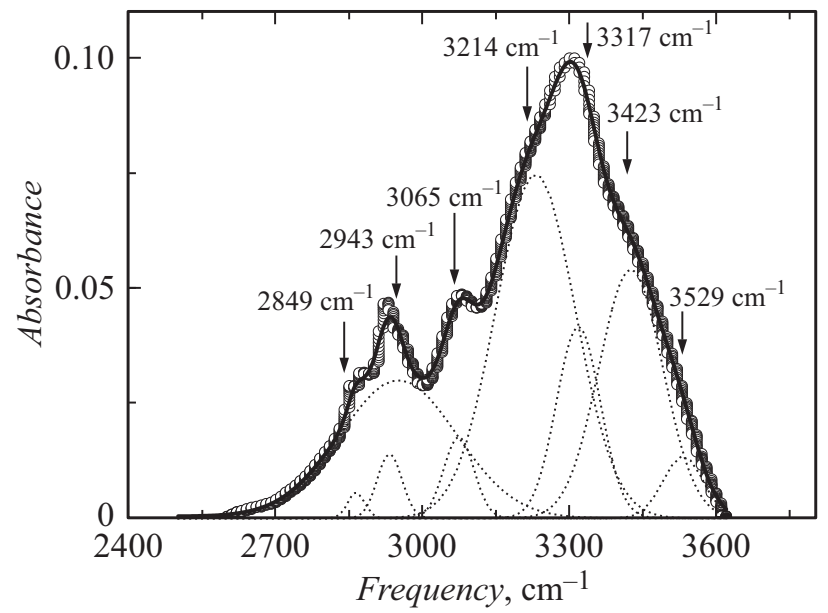

Рис. 1. Спектр полосы Амид А здорового человека и разложение на гауссовы компоненты. Кружки - эксперимент, пунктирными линиями показаны гауссовы контуры, жирная сплошная линия - огибающая гауссовых контуров.

ная по поверхности плотность для области, занимаемой кальцинатами, измеряемая в единицах Хаунсфилда [5], умножается на общую площадь кальцинатов. В работе приведена типичная для всех исследованных отложений кривая рентгеновской дифракции образцов кальцинатов пациента средней тяжести (индекс Агатсона 143) (см также [1]). Регистрация ИК-спектров поглощения непрозрачных образцов проведена с помощью приставки НПВО с однократным отражением и рабочим элементом из материала ZnSe (ATR sampling accessory) с разрешением $4 \mathrm{~cm}^{-1}$ на фурье-спектрометре Nicolet-6700 (число сканов выбиралось в пределах 30-100). Измерения выполнены на приборах ресурсного центра СПбГУ Geomodel. В этом методе спектры измеряются для слоя толщиной порядка длины световой волны, т.е. при записи спектров аорты захватываются именно ее субэндотелиальные области.

На рис. 1 представлен фрагмент спектра ИК-поглощения клапана здорового мужчины с целью использования его в качестве базового для дальнейшего сравнения. Для его анализа воспользуемся алгоритмом метода наименьших квадратов [6] для наилучшей нелинейной подгонки эксперимента гауссовыми контурами. Результат этой процедуры представлен на рис. 1 пунктирными кривыми гауссовых контуров и сплошной кривой их огибающей. Видно, что для успешной подгонки достаточно восьми контуров. При этом среднеквадратичное отклонение составляет величину не более $0.01 \%$. Контуры с максимумами при 2849 и $2943 \mathrm{~cm}^{-1}$ соответствуют хорошо известным полосам поглощения метил-метиленовыми группами, которые, как правило, не участвуют в формировании Н-связей и по этой причине исключены из дальнейшего рассмотрения. Полоса при $3065 \mathrm{~cm}^{-1}$ соответствует поглощению валентными колебаниям аминокислотных $\mathrm{NH}_{2}$-групп, которые хотя и охватываются
Н-связями, но по причине, указанной выше, оказываются также вне рамок анализа. Зато полоса при $3214 \mathrm{~cm}^{-1}$ может быть отнесена к поглощению ОН-группой, участвующей в образовании Н-связи. Именно параметры контура этой полосы использованы в дальнейшем для оценки величины энергии Н-связи. Дополнительным подтверждением предложенной интерпретации является установленное ранее соответствие полосы при $3317 \mathrm{~cm}^{-1}$ валентным колебаниям NH-группы коллагена [7,8] и полос при 3423 и $3529 \mathrm{~cm}^{-1}$ валентным колебаниям групп -OH [8]. Контур при $3317 \mathrm{~cm}^{-1}$ типичен для валентных колебаний NH-группы коллагена [7,8]. Воспользуемся теперь полученными нами значениями величин частот колебаний ОН-групп для оценки величин энергий комплексов с водородной связью типа ОН. ...А по величине сдвига этих частот от частоты валентных колебании

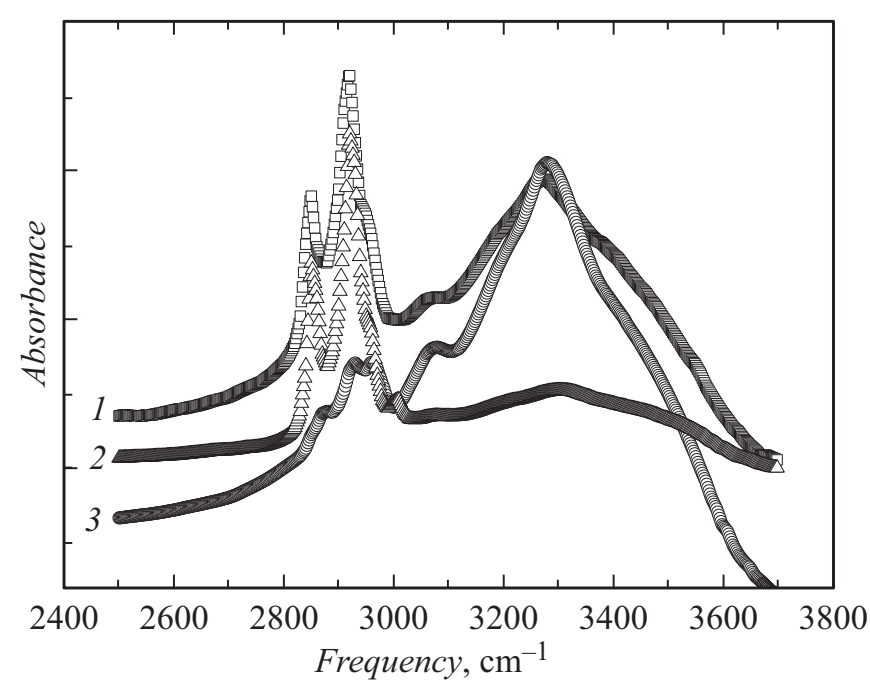

Рис. 2. Спектры полосы Амид А для поврежденного кальцинозом аортального клапана $(1)$, кости (2) и створки аортального клапана здорового человека (3).

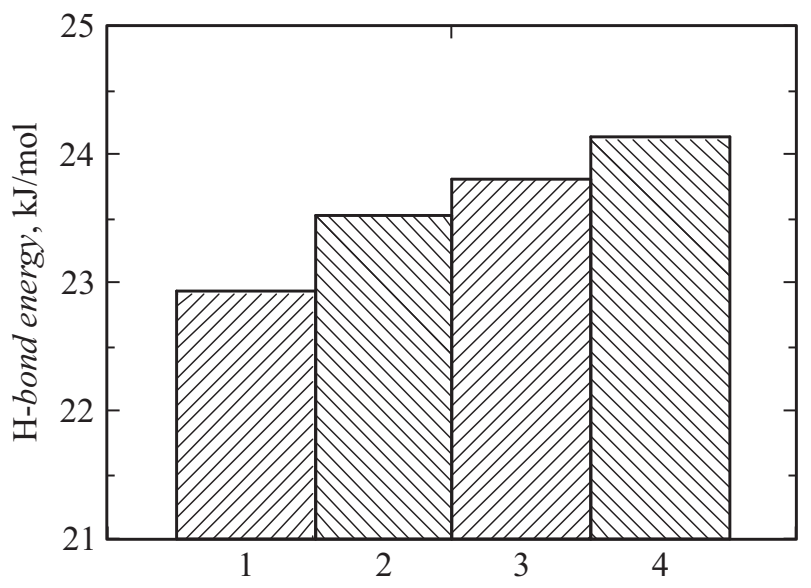

Рис. 3. Сравнительная диаграмма энергий Н-связей. 1 - клапан здорового человека, 2 - аорта, поврежденная стенозом, 3 - синтетический коллаген, 4 - кость. 
Энергии Н-связей в клапанах здорового человека

\begin{tabular}{c|c|c}
\hline Частоты ОН-групп, $\mathrm{cm}^{-1}$ & $\begin{array}{c}\text { Сдвиг частоты ОН-групп, } \\
\mathrm{cm}^{-1}\end{array}$ & $\begin{array}{c}\text { Энергия H-связи, } \\
\mathrm{kJ} / \mathrm{mol}\end{array}$ \\
\hline $3214 \pm 25$ & 421 & 22.9 \\
$3423 \pm 15$ & 227 & 15.8 \\
$3529 \pm 18$ & 121 & 7.1
\end{tabular}

свободных от Н-связей ОН-групп $\left(3650 \mathrm{~cm}^{-1}\right)$ [3]. Пользуясь теперь эмпирическим корреляционным соотношением между сдвигом частоты и величиной энергии образования водородной связи [6], проведем ее оценку. Полученные таким образом результаты представлены в таблице. Видно, что в сердечном клапане здорового человека энергия Н-связи близка к ее энергии в воде $(20-25 \mathrm{~kJ} / \mathrm{mol}[9])$.

Представляется интересным сравнить данные для образца тканей аортального клапана здорового человека с аналогичными данными для его кости, а также с данными для поврежденного клапана аорты. Соответствующие спектры представлены на рис. 2. Все три спектра сохраняют в основном свою форму, но сильно различаются по взаимному вкладу в поглощение в областях спектра, связанных с ОН- и $\mathrm{NH}_{2}$-группами с одной стороны и метил-метиленовыми с другой. Обращает на себя внимание близкая аналогия спектров ткани поврежденного клапана аорты и кости. Видно также, как отличаются они от спектра здоровой ткани. Это отличие может быть интерпретировано как свидетельство того, что поражение аорты происходит по механизму зарождения элементов костной ткани в субэндотелиальных структурах аорты. Перейдем теперь от качественной характеристики спектров на рис. 2 к количественной. С этой целью подвергнем их процедуре, использованной выше для анализа формы спектральных полос на рис. 1. Результат оценки величины энергий Н-связей представлен на рис. 3 в виде диаграммы. На этой диаграмме приведена для сравнения энергия для синтетического обезвоженного коллагена.

Видно, что энергия Н-связи между гидроксильными группами достигает своего максимального значения в костной ткани, при этом она превышает даже ее величину в синтетическом коллагене. Такое увеличение энергии (по абсолютной величине) отвечает уменьшению расстояния между соответствующими гидроксильными группами, а значит, большей плотности белковой ткани в рассматриваемом случае.

Таким образом, полученные результаты свидетельствуют в пользу образования в субэндотелиальных структурах аортальных полулуний элементов костной ткани у пациентов с кальцинированным аортальным стенозом.

Вывод о значимости и применимости предложенного метода напрашивается.
Настоящая статья не содержит каких-либо исследований с использованием людей и животных в качестве объектов исследования.

\section{Конфликт интересов}

Авторы заявляют, что у них нет конфликта интересов.

\section{Список литературы}

[1] Ястребов С.Г., Гуляев Н.И., Галенко А.С., Прус М., Сиклицкая А.В. // Письма в ЖТФ. 2019. Т. 45. В. 4. С. 46-48.

[2] Гуляев Н.И., Жуков М.В., Куранов Г.Л., Борисов Ю.А., Суглобова Е.Д., Ястребов С.Г., Пелешок А.С. // Ульяновск. мед.-биол. журн. 2017. № 1. С. 23-31.

[3] Libowitzky E. // Monatsh. Chem. 1999. V. 130. N 8. P. $1047-$ 1059.

[4] Иванов-Омский В.И. // Письма в ЖТФ. 2014. Т. 40. В. 16. C. 29-35.

[5] Hoffmann U., Brady T.J., Muller J. // Circulation. 2003. V. 108. N 8. P. e 50-e 53.

[6] Marquardt D.W. // SIAM J. Appl. Math. 1963. V. 11. N 2. P. 431-441.

[7] Kudo S., Ogawa H., Yamakita E., Watanabe Sh., Suzuki T., Nakashima S. // Appl. Spectrosc. 2017. V. 71. N 7. P. 16211632.

[8] Movasaghi Z., Rehman S., Rehman Ih. // Appl. Spectrosc. Rev. 2008. V. 43. N 2. P. 134-179.

[9] Suresh S.J., Naik V.M. // J. Chem. Phys. 2000. V. 113. N 21. P. 9727-9732. 